\title{
PROSES AUTO VISUAL INSPEKSI PADA ENGINE PISTON DENGAN APLIKASI KAMERA DAN ROBOT YANG TERINTEGRASI
}

\author{
${ }^{*}$ Rahmat Kartolo1, Fadli Hadi Purnomo² \\ ${ }^{1}$ Engineering Dept. Head \\ 2RnD Dept. Head \\ PT Astra Otoparts Tbk Divisi Winteq \\ ^Email : rahmat3110@yahoo.com, fadli95@gmail.com
}

\begin{abstract}
Abstrak
Proses inspeksi merupakan hal yang terpenting dalam suatu proses produksi, hal ini menentukan produk tersebut dapat diterima oleh konsumen atau tidak. Banyak industri di Indonesia dalam proses inspeksi ini masih secara manual, yaitu dengan indera manusia. Tentulah sangat berkaitan dengan kelelahan, kejenuhan dan daya konsentrasi atau biologis tubuh manusia. Sehingga mempengaruhi kualitas dan produktifitas dari suatu produk. Industri komponen kendaraan tidak lepas dari kondisi tersebut, salah satu industri pembuatan engine piston. Komponen ini merupakan komponen yang sangat penting dan presisi pada sebuah mesin, sehingga menuntut proses inspeksi yang ketat.

Teknologi Vision Sensor pada saat ini berkembang dengan pesat, teknologi ini bermuara pada pengolahan data pada gambar (image processing) yang diambil oleh sensor, berupa laser ataupun camera. Secara umum dari hasil image processing tersebut dapat digunakan untuk kebutuhan Guide, Inspect, Gauge, Identification (GIGI).

Dengan ketatnya tuntutan kualitas dan produktifitas di industri pembuatan engine piston ini, maka Vision Sensor dapat menjadi salah satu solusinya. Diantara tuntutan kualitas engine piston tersebut diantaranya piston harus bebas dari cacat permukaan seperti penyok, goresan, kusam, yang tersebar di beberapa bagain permukaan piston, seperti bagian kepala, sisi samping,lubang pin sampai dengan 23 item. Piston juga sebagai komponen yang sangat presisi membutuhkan penanganan yang harus hati-hati terutama pada saat inspeksi, oleh sebab itu penanganannya menggunakan robot 6-axis. Pada proses inspeksi engine piston ini juga dibutuhkan sistem pengolahan data informasi yang menunjukkan piston mana dan bagain apa yang terdapat cacat, juga sebagai umpan balik kepada proses sebelumnya, sehingga setiap cacat yang ditemukan dapat langsung memberikan informasi sebagai inisialisasi perbaikan.

Kata Kunci: Engine Piston, Vision Sensor; Robot 6-axis; Pengolahan Data Informasi.
\end{abstract}

\section{Pendahuluan}

Piston merupakan komponen utama ruang bakar dalam kendaraan bermotor, berfungsi merubah energi kimia menjadi energi mekanik. Piston ini berhadapan langsung dgn proses pembakaran yang biasanya dapat mencapai suhu $350^{\circ} \mathrm{C}$, menderita gaya dan tekanan yang tinggi sebagai akibat tekanan ledakan hasil pembakaran. Piston ini harus bergerak bolak-balik dengan kecepatan yang berubah-ubah sesuai dengan tekanan pedal gas bekerja pada putaran tinggi s/d 10.000 rpm[1]. Sehingga piston ini didesign sangat presisi dan melalui proses inspeksi visual yang ketat.

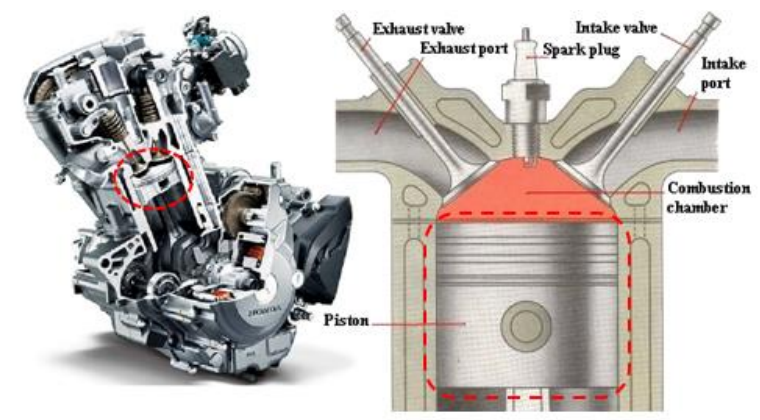

Gambar 1 Piston pada mesin bakar

Di industri manufaktur piston, proses inspeksi visual dilakukan diakhir proses dari perjalanan produksi piston. Semua tipe piston akan melalui fase visual inspeksi sebagai bagian dari proses produksi sebelum fase pengiriman. Kritisnya fase ini menjadikan semua unit yang terlibat di dalamya menjadi representasi kualitas produk piston secara keseluruhan tersebut.

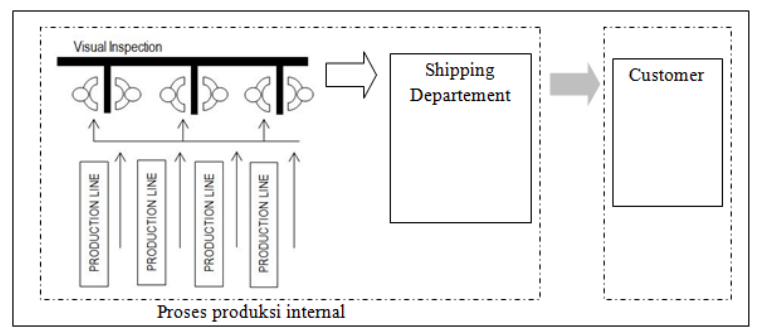

Gambar 2 Alur kerja inspeksi visual

Proses inspeksi visual secara manual hanya dapat dilakukan pada waktu tertentu, yaitu pada shift 2 (07.00-16.00) dan shift 3 (16.00-24.00) terkait dengan daya tahan manusia dan waktu biologis. Sehingga produktifitas produksi sangat dipengaruhi oleh proses inspeksi visual. Mengenai waktu biologis manusia, dalam ergonomi sistem 
kerja yang menggunakan indera atau tubuh manuisa memiliki karekteristik sendiri, ada yang disebut dengan fit the job to the man. Tubuh manusia memiliki ritme biologis dimana pada jamjam tertentu fungsi tubuh dapat berfungsi secara maksimal ataupun tidak efektif. Rtime biologis dipengaruhi internal tubuh manusia sendiri dan external. Faktor internal merupakan faktor yang berasal dari dalam diri individu. Beberapa peneliti percaya bahwa pusat internal dari ritme ini terletak di suatu area di otak, sedangkan faktor eksternal berhubungan dengan lingkungan natural di luar tubuh seperti siklus gelap-terang (siang-malam), suhu ruang, perubahan-perubahan musim, interaksi sosial dengan indivisu yang lain serta waktu/jam makan yang semuanya mempengaruhi siklus aktivitas fungsi-fungsi tubuh[2]. Terkait dengan itu agar proses inspeksi visual tersebut dapat efektif maka dibutuhkan proses otomasi yang dapat mewakili proses manual oleh tubuh manusia.

Teknologi Vision sensor dengan menggunakan kamera dapat menjadi alternatif yang dapat digunakan di banyak rekayasa teknik termasuk menggantikan inspeksi visual manual menjadi otomatis. Kamera sebagai salah satu vision sensor, merupakan seperangkat sistem yang memiliki fungsi untuk mengambil suatu objek menjadi sebuah gambar yang merupakan hasil proyeksi pada sistem lensa. Dalam dunia industri kamera digunakan dalam berbagai hal aplikasi, misalnya inspeksi, monitoring, pengecekan, pengarah posisi, dan masih banyak lagi.

Dalam proses inspeksi visual ini dibutuhkan alat untuk penanganan produk yang cukup presisi, agar kualitas produk tetap terjaga. Robot, salah satu aktuator yang memiliki keterulangan dan kepresisian yang baik. Robot industri atau disebut robot lengan pada dasarnya hanyalah gabungan dari motor dan system mekanik yang dikendalikan oleh perangkat kendali untuk bergerak berdasarkan target yang telah diprogram sebelumnya.

\section{Tujuan Penulisan Makalah}

Dalam makalah ini akan disampaikan beberapa hal penting yang diperhatikan dalam :

a. Mengaplikasikan Vision Sensor sebagai fungsi penanganan material dan inspeksi visual secara otomatis.

b. Pengolahan data inspeksi, agar mudah telusur dan terkini.

\section{Batasan Pembahasan}

Adapun batasan yang akan dibahas dalam makalah ini, yaitu :

a. Aplikasi Vision Sensor sebagai pengarah robot 6-axis untuk penanganan engine piston secara otomatis.

b. Pemilihan metoda Vision Sensor sebagai alat insepksi visual pada cacat permukaan di engine piston secara otomatis.

c. Proses pengolahan data hasil inspeksi visual dengan Vision Sensor pada engine piston sehingga didapat data jumlah dan jenis kontribusi caacat permukaan yang terjadi.

\section{Metodologi Penulisan Makalah}

\subsection{Studi Lapangan}

Astra Otoparts sebagai produsen komponen otomotif memiliki anak perusahaan yang khusus memproduksi engine piston yang saat ini memiliki kapasitas produksi sebagai berikut :

$\begin{array}{ll}\text { Total produksi/hari } & : \text { : } 2.000 \text { Piston } \\ \text { Terdiri dari : } & \\ \text { Tipe Motor } & : \text { 33.300 Piston/hari } \\ \text { Tipe Gasoline } & : \text { 4.200 Piston/hari } \\ \text { Tipe Diesel } & : \text { 4.500 Piston/hari }\end{array}$

Adapun waktu produksinya dilakukan selama : Jam Kerja Produksi : 3 Shift/hari Jam Kerja Inspeksi Visual: 2 Shift/hari

Kondisi tersebut melahirkan tuntutan proses otomasi pada proses inspeksi visual, dengan target dapat meningkatkan produktivitas dan menjaga kestabilan kualitas produk. Dari data diatas, tipe piston yang akan diotomastiskan proses inspeksi visualnya yaitu piston sepeda motor tipe KZLN. Dengan pertimbangan tipe piston ini yang paling banyak diproduksi.

Engine Piston memeliki anatomi atau area yang dibagi berdasarkan proses pembuatan dan fungsinya, diantaranya : 


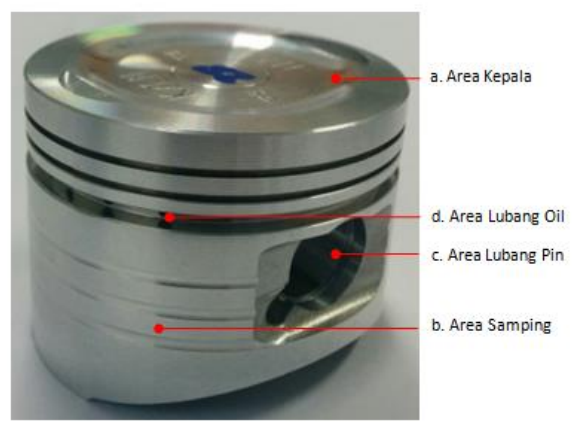

Gambar 3 Pembagian Area Piston

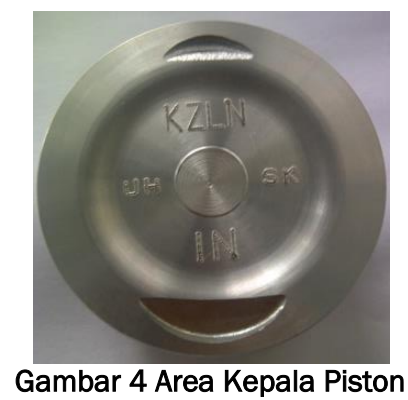

a. Area Kepala, pada area ini yang diinspeksi adalah :

1. Tulisan benar atau salah (lengkap atau tidak),

2. Tulisan tipe terbalik atau tidak,

3. Baret,

4. Penyok,

5. Ada Chamfer atau tidak,

6. Monoiri,

7. SU di kepala,

8. SU di lembah,

9. Nokori casting,

10. Blow Hole,

b. Area Samping, pada area ini yang diinspeksi adalah :

11. Baret,

12. Out Diamater Finish (ODF) penyok,

13. Ring Groove Penyok,

14. Sekrap di ring groove,

15. SU,

c. Area Lubang Pin, pada area ini yang diinspeksi adalah :

16. Baret,

17. Nokori,

18. SU,

d. Area Lubang Oli, pada area ini yang diinspeksi adalah :

19. Drill Displacement,

20. Drill Slip,

21. Drill Not Through,

22. No Drill Hole,

\section{Drill Not Complete}

Hal yang perlu diperhatikan juga selama melakukan inspeksi visual adalah piston tidak boleh langsung disentuh oleh tangan operator dan harus ditangani dengan hati-hati, karena penanganan yang tidak baik dapat menyebabkan cacat.

\subsection{Studi Literatur}

\subsubsection{Kamera sebagai Vision Sensor}

Beberapa fungsi kamera sebagai vision sensor, diantaranya :

a. Guide, kamera sebagai pengarah sistem.

b. Inspect, kamera sebagai alat inspeksi.

c. Identification, kamera sebagai alat untuk mengenali suati objek.

d. Gauge, kamera sebagai alat ukur.

Parameter dari sebuah sistem aplikasi sensor kamera terdiri dari :
a. Kamera
b. Lensa
c. Metode Pencahayaan

Istilah pada sistem kamera :
a. Working Distance (WD), jarak benda kerja dengan kamera

b. Field-of-View (FOV), luasan area yang terambil gambarnya oleh kamera

c. Depth-of-Field (DOV), kedalamam objek yang diambil gambarnya

d. Resolution,

e. Accuracy, ketelitian kamera dalam mengolah objek gambar.

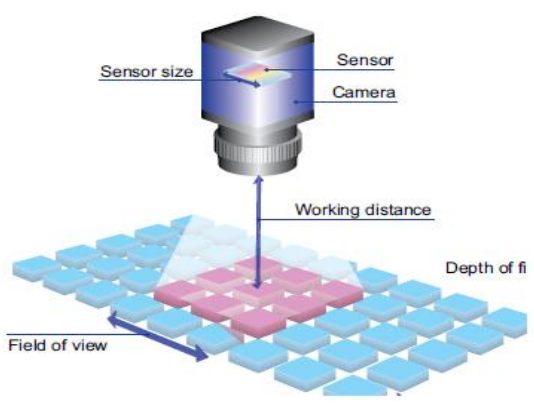

Gambar 5 Istilah Pada Sistem Kamera

Pada aplikasi kamera, dikenal beberapa metode pencahayaan yang digunakan, diantaranya :
1. Bright Field
2. Dark Field
3. Back Lighting
4. Diffuse Dome
5. Axial Diffuse 


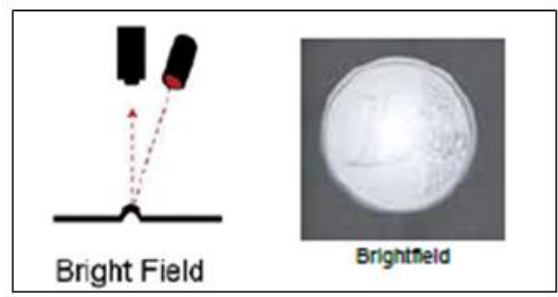

Gambar 6 Pencahayaan tipe Bright Field

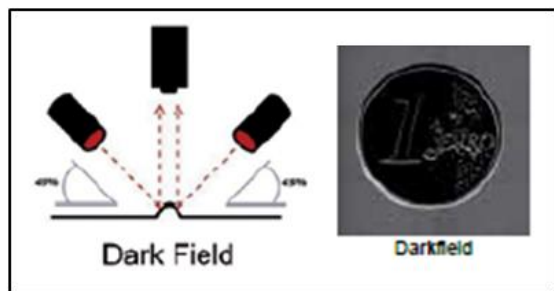

Gambar 7 Pencahayaan tipe Dark Field

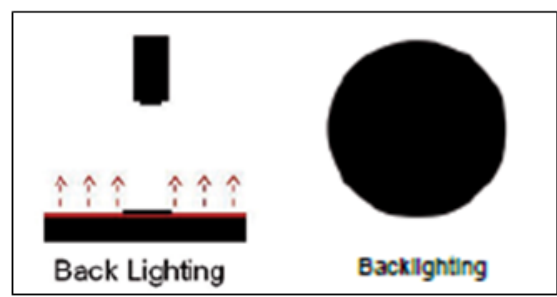

Gambar 8 Pencahayaan tipe Back Lighting

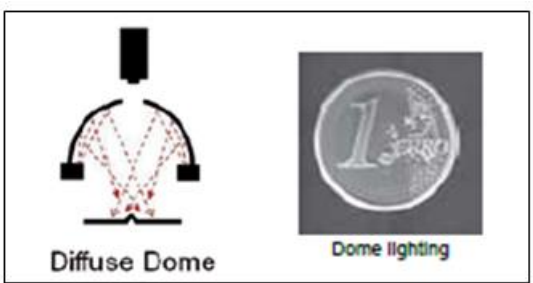

Gambar 9 Pencahayaan tipe Diffuse Dome

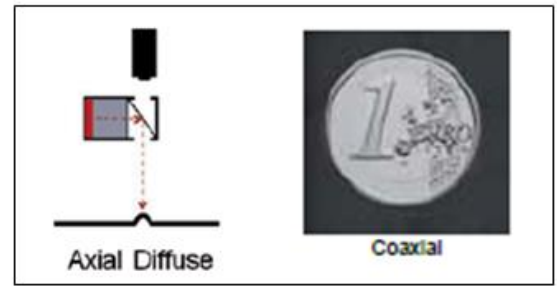

Gambar 10 Pencahayaan tipe Axial Diffuse

\subsubsection{Robot industri 6-axis}

Defini robot industri, yaitu suatu alat atau mesin yang dapat melakukan tugas fisik, baik menggunakan pengawasan / control manusia, ataupun menggunakan program yang telah didefinisikan, dapat di program kembali dan memiliki minimal 3 derajat kebebasan.
Beberapa tipe robot industri, diantaranya :

a. Cartesian robot adalah robot yang dapat melakukan 3 translasi dengan menggunakan Linear Slides.

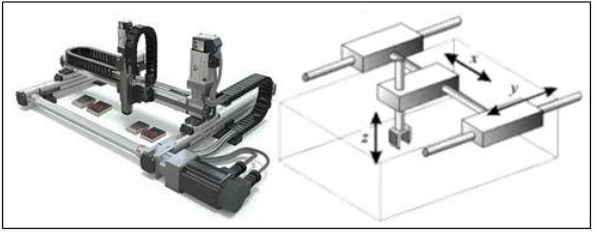

Gambar 11 Cartesian Robot

b. Scara robot adalah robot yang dapat melakukan 3 translasi plus satu rotasi pada sumbu vertikal.

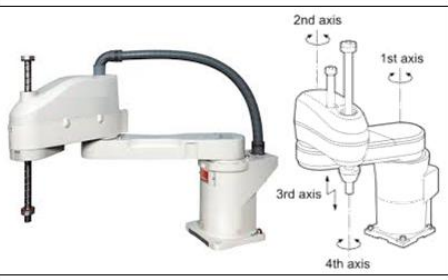

Gambar 12 Scara Robot

c. Robot 6-axis adalah robot yang sepenuhnya dapat bergerak dengan memiliki 3 translasi dan 3 rotasi.

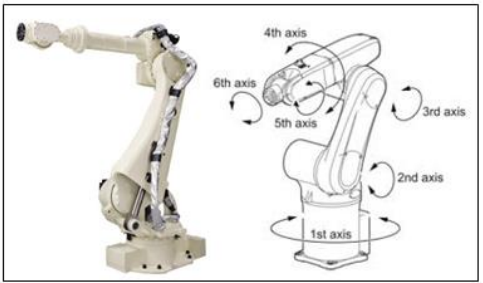

Gambar 13 Robot 6-axis

d. Delta robot adalah sepert laba-laba, dibangun dari jajaran genjang yang bersendi dan terhubung ke satu base, memiliki satu end effector dan bertranslasi $\mathrm{x}, \mathrm{y}, \mathrm{z}$ tanpa rotasi, biasa digunakan dalam area kerja yang berbentuk kubah seperti makanan, farmasi, dan komponen elektrik.

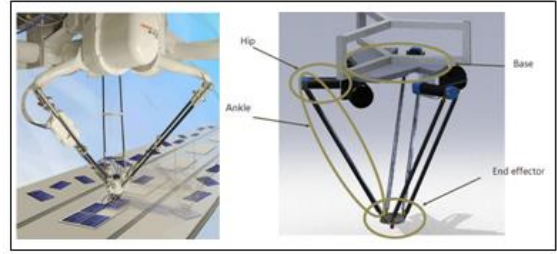

Gambar 14 Delta Robot

e. Dual arm Robot adalah robot yang terdiri dari dua buah lengan yang dapat bekerja sama pada benda kerja yang diberikan. 
Seminar Nasional Instrumentasi, Kontrol dan Otomasi (SNIKO) 2015 Bandung, Indonesia, 10-11 Desember 2015

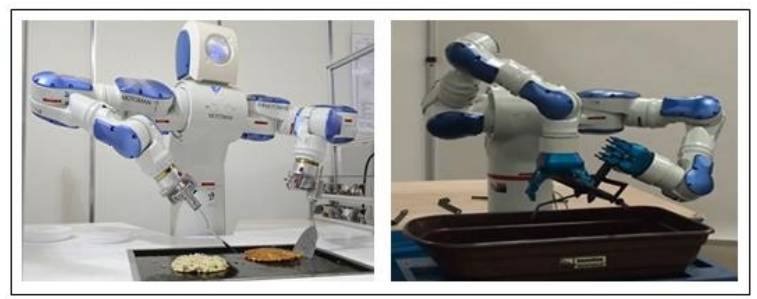

Gambar 15 Dual Arm Robot

Mengenal Pergerakan Robot 6-axis, diantaranya :

- Interpolasi Joint, robot bergerak berdasarkan perintah pada axis-axis robot.

- Interpolasi Linear Robot, robot bergerak berdasarkan perintah secara garis lurus suatu titik ke titik lainnya.

- Interpolasi Linear Tool, robot bergerak berdasrkan perintah tool (gripper) dari satu titik ke titik lainnya.

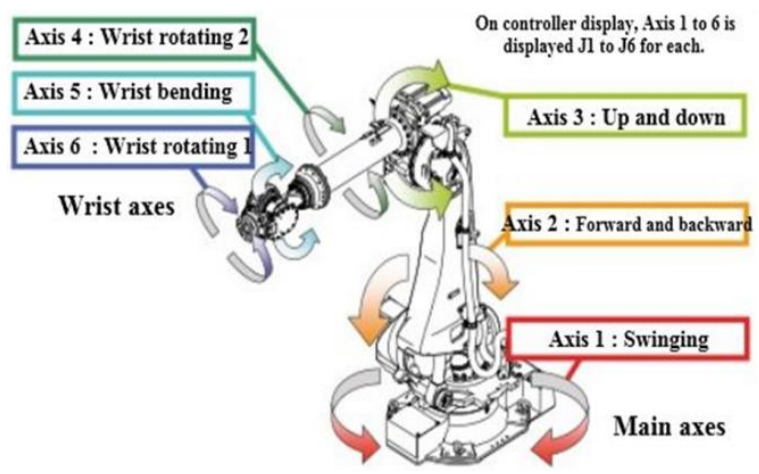

Gambar 16 Axis pada Robot 6-axis

\section{Pembahasan dan Hasil Makalah}

\subsection{Penanganan Material}

Untuk penanganan piston pada saat akan di inspeksi secara otomatis digunakan aplikasi Vision Guide Robot (VGR), yaitu kamera difungsikan sebagai pengarah robot agar dapat menempatkan piston pada posisi orientasi yang acak (dari keranjang) ke posisi tertentu, sehingga piston dapat duduk tepat di atas fixture. Beberapa tahapan proses yang dilakukan dalam aplikasi Vision Guide Robot, diantaranya :

Tahapan pertama mastering, dilakukan pengamabilan gambar objek piston di station oreintasi dengan oreintasi tertentu (nol derajat) yang telah disesuaikan dengan kebutuhan posisi fixture. Disini digunakan salah satu objek gambar sebagai penentu yaitu arah valve piston. Lighting diatur ketinggiannya terhadap permukaan atas benda kerja agar menghasilkan gambar seperti gambar di bawah ini.

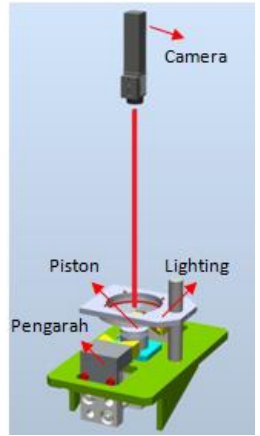

Gambar 18 Posisi Camera dengan Piston di statiun orientasi

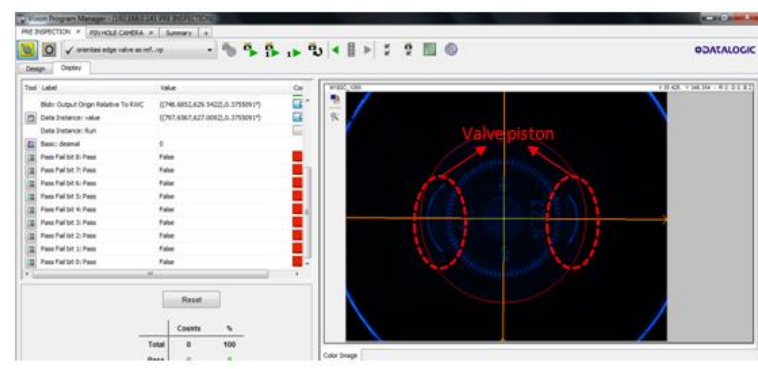

Gambar 19 Gambar Master

Tahapan kedua alignment robot, memposisikan gipper robot sejajar dan satu sumbu serta satu oreintasi diatas piston master kemudian menyimpan posisi tersebut di program robot, sebagai nol derjat gripper.

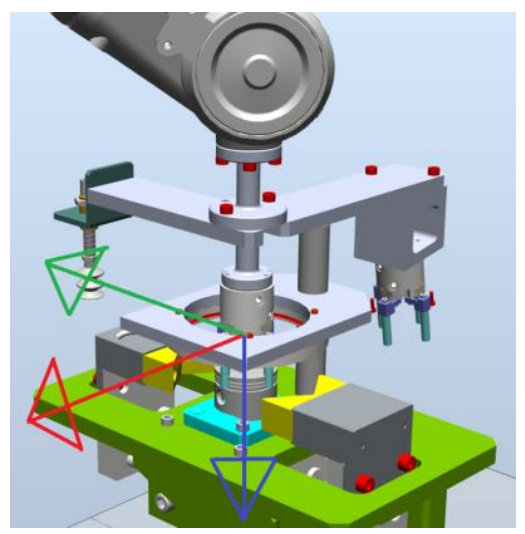

Gambar 20 Alignment Robot

Hal yang menunjang kestabilan sistem VGR adalah penggunaan yang tepat pada instruksi program serta kesesuaian dengan arah gerak robot. Pada robot 6-axis terdapat arah gerak X Y dan Z. Pada gambar dibawah arah $X$ ditunjukan garis panah berwarna merah, $\mathrm{Y}$ berwarna hijau dan $\mathrm{Z}$ berwarna biru. Penyesuaian orientasi berada pada arah Z, dimana garis biru yang dibentuk dalam ilustrasi diatas merupakan sumbu putar orientasi. Pada robot ABB sumbu putar $Z$ disebut dengan istilah RZ.

Adapun instruksi pada robot yang merupakan proses penyesuaian adalah sebagai berikut: 
Seminar Nasional Instrumentasi, Kontrol dan Otomasi (SNIKO) 2015 Bandung, Indonesia, 10-11 Desember 2015

$$
\frac{\text { MoveL RelTool (TAKE_ORIENTATION_CAM,0,0,0 }}{\mathrm{a}} \frac{\text { RRz:=sudut) }}{\mathrm{b}}
$$

a. Pergerakan linear (lurus)

b. Posisi berada tepat di titik target TAKE ORIENTATION (titik 0,0,0)

c. Pada titik target tersebut, putar orientasi sesuai sumbu Z dengan nilai derajat sesuai variabel "sudut".

Adapun alur kerja dari system VGR dalam penelitian ini adalah sebagai berikut:

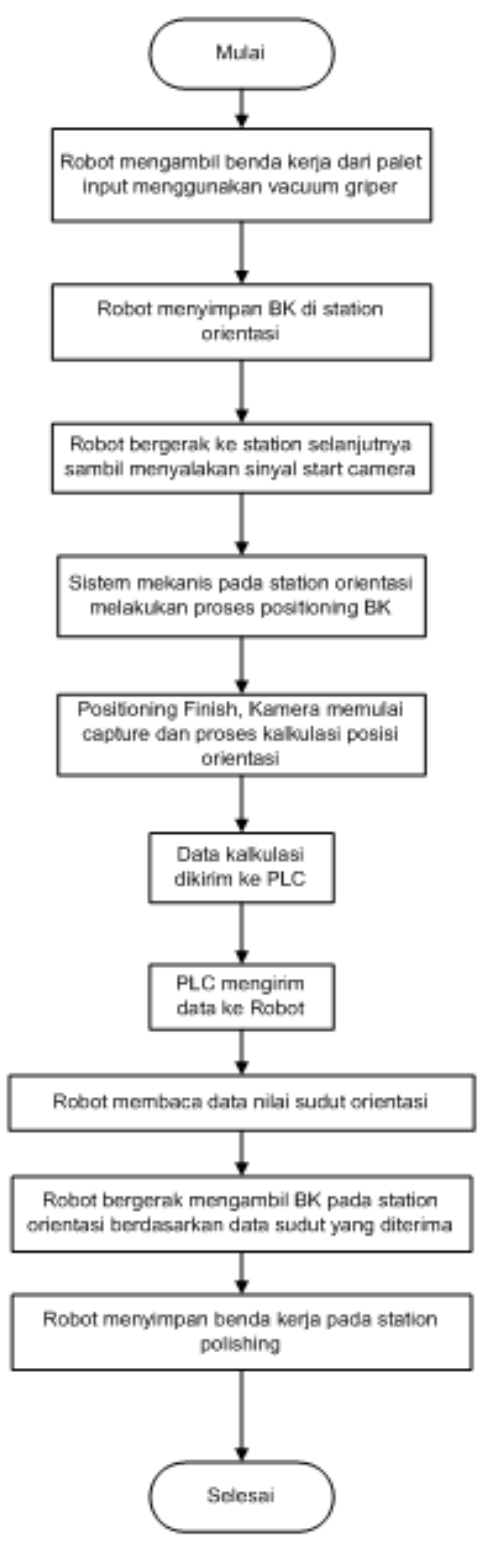

Gambar 21 Alur Kerja VGR

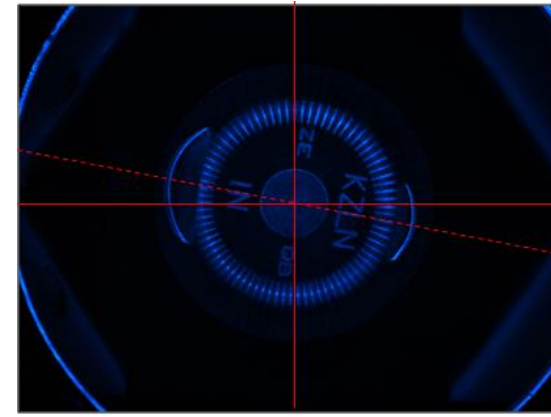

Gambar 22 Orientasi Piston yang menyimpang

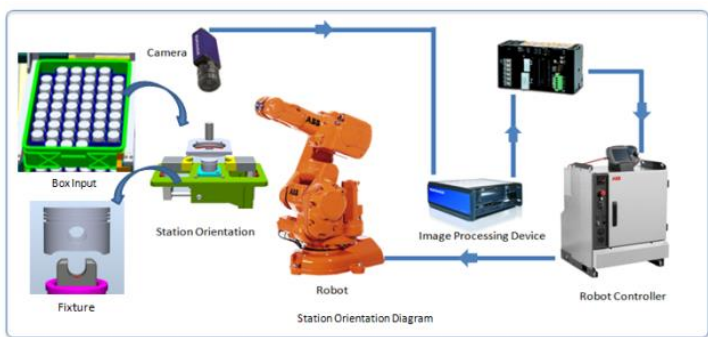

Gambar 23 Diagram Sistem VGR

\subsection{Aplikasi Kamera untuk Inspeksi Visual secara Otomtis}

Dari hasil pengelompokan metode check pada jenis cacat permukaan pada piston diperoleh :

\begin{tabular}{|c|c|c|c|c|}
\hline \multirow{2}{*}{ Area Check } & \multicolumn{4}{|c|}{ Fungsi Check } \\
\hline & Guide & Inspect & Gauge & Identify \\
\hline \multicolumn{5}{|l|}{ a. Area Kepala, } \\
\hline 1. Tulisan benar atau salah (lengkap atau tidak). & & & & $\sqrt{ }$ \\
\hline 2. Tulisan tipe terbalik atau tidak, & & & & $\sqrt{ }$ \\
\hline 3. Baret, & & $\sqrt{ }$ & & \\
\hline 4. Penyok, & & $\sqrt{ }$ & & \\
\hline 5. Ada Chamfer atau tidak, & & $\sqrt{ }$ & & \\
\hline 6. Monoiri, & & $\sqrt{ }$ & & \\
\hline 7. SU di kepala, & & & & $\sqrt{ }$ \\
\hline 8. SU di lembah, & & & & $\sqrt{ }$ \\
\hline 9. Nokori casting, & & & & $\sqrt{ }$ \\
\hline 10. Blow Hole, & & & & $\sqrt{ }$ \\
\hline \multicolumn{5}{|l|}{ b. Area Samping, } \\
\hline 11. Baret, & & $\sqrt{ }$ & & \\
\hline 12. Out Diamater Finish (ODF) penyok, & & $\sqrt{ }$ & & 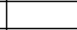 \\
\hline 13. Ring Groove Penyok, & & $\sqrt{ }$ & & \\
\hline 14. Sekrap di ring groove, & & & & $\sqrt{ }$ \\
\hline 15. SU, & & & & $\sqrt{ }$ \\
\hline \multicolumn{5}{|l|}{ c. Area Lubang Pin, } \\
\hline 16. Baret, & & $\sqrt{ }$ & & \\
\hline 17. Nokori, & & & & $\sqrt{ }$ \\
\hline 18. SU, & & & & $\sqrt{ }$ \\
\hline \multicolumn{5}{|l|}{ d. Area Lubang Oli, } \\
\hline 19. Drill Displacement, & & $\sqrt{ }$ & & \\
\hline 20. Drill Slip, & & $\sqrt{ }$ & & \\
\hline 21. Drill Not Through, & & & & $\sqrt{ }$ \\
\hline 22. No Drill Hole, & & & & $\sqrt{ }$ \\
\hline 23. Drill Not Complete & & $\sqrt{ }$ & & \\
\hline
\end{tabular}

\section{Gambar 24 Tabel Metode Check}

Dari tabel diatas, dapat diambil referensi untuk penggunaan metode pencahayaannya adalah :

Bright Feild, Diffuse Dome untuk Inspeksi dan Axial Difuse untuk Identifikasi.

Kemudian untuk menentukan resolusi kamera, dengan kebutuhan FOV (area yang akan diinspeksi) $\pm 30 \times 30 \mathrm{~mm}$, dengan keakurasian yang dibutuhkan 30 mikron, maka dibutuhkan 
Seminar Nasional Instrumentasi, Kontrol dan Otomasi (SNIKO) 2015 Bandung, Indonesia, 10-11 Desember 2015

kamera dengan resolusi sekitar 1,5 Mega Pixel (MP). Sehingga diperoleh kebutuhan kamera dan lightingnya :

A. Area Kepala; menggunakan 2 jenis kamera

Kamera 1 : M150, Gig-E, 1296 x 966, 30 FPS, Grayscale, 1/3" CCD Datalogic

Lens: Reguler Lens

Deteksi : Baret,Penyok, Monoiri,SU,Nokori casting,Blow Hole

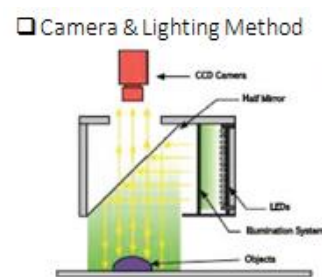

Axial Diffuse

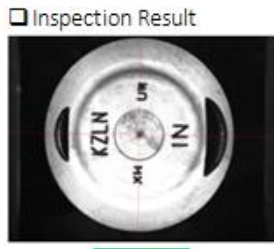

OK

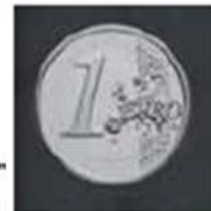

Coaxial

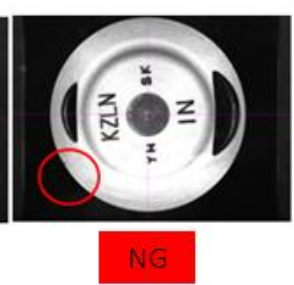

Gambar 25 Pencahayaan dan Hasil Gambar Kamera 1

Kamera 2 : M150, Gig-E, 1296 x 966, 30 FPS, Grayscale, 1/3" CCD Datalogic

Lens: Reguler Lens

Deteksi : Tulisan, Chamfer

\section{- Camera \& Lighting Method}

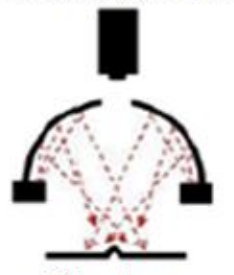

Diffuse Dome

$\square$ inspection Result

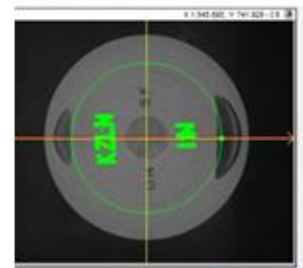

$\square K$

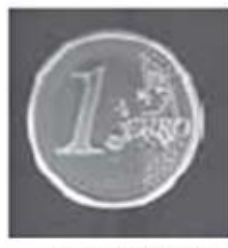

Dome Lighting

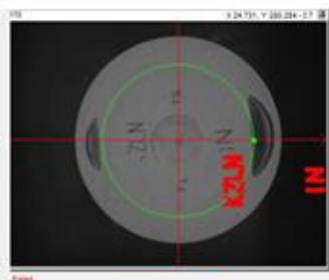

N曰
Gambar 26 Pencahayaan dan Hasil Gambar Kamera 2

B. Area Samping; menggunakan 2 kamera yang sama untuk inspeksi sisi kanan dan sisi kiri

Kamera 3 : M180C, Gig-E, 1628 x 1236, 20 FPS, Color, 1/1.8" CCD Datalogic
Lens: Reguler Lens

Deteksi : Baret,penyok,Sekrap di ring groove, SU

$\square$ Camera \& Lighting Method
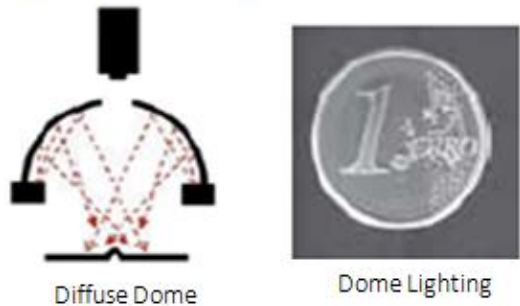

Inspection Result
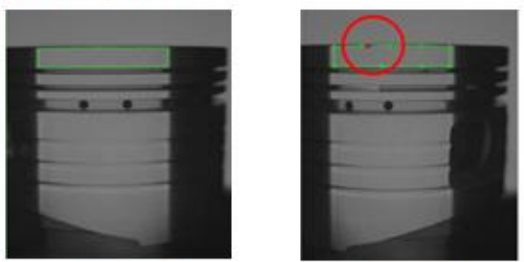

OK

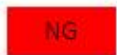

Gambar 27 Pencahayaan dan Hasil Gambar Kamera $3 \& 4$

C. Area Lubang Pin, menggunakan 1 camera

Kamera 5 : M180C, Gig-E, 1628 x 1236, 20

FPS, Color, 1/1.8" CCD Datalogic

Lens: Catadioptric Lens

Deteksi : Baret, Nokori, SU

aCamera \& Lighting Method
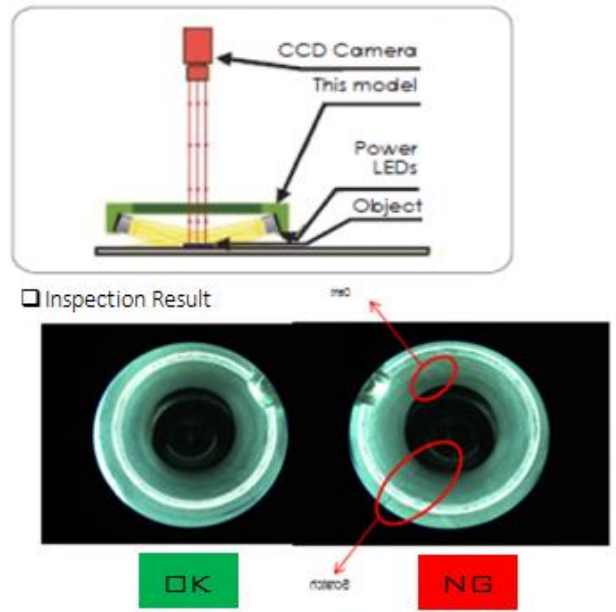

Gambar 28 Pencahayaan dan Hasil Gambar Kamera 5

D. Area Lubang Oli, menggunakan 1 camera Kamera $6: 1722$ Smart Camera 2 MP National Instrument

Lens : Regular Lens

Deteksi : Drill Displacement, Drill Slip, Drill Not Through, No Drill Hole, Drill Not Complete 


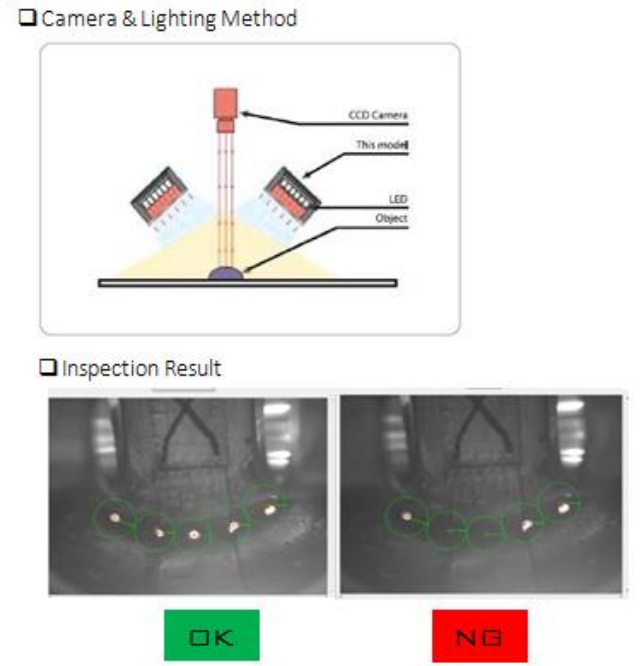

Gambar 29 Pencahayaan dan Hasil Gambar Kamera 6

\subsection{Sistem Pengolahan Data pada Aplikasi Inspeksi Visual secara Otomatis}

Pada sistem ini pengolahan data dilakukan oleh satu unit Personal Computer. Software antar muka (Interface) dengan pengguna atau operator menggunakan aplikasi Labview dari National Instrument. Dari topologi jaringan yang diterapkan pada sistem ini, Image yang diterima oleh camera diproses oleh camera controller. Image ini di transformasikan dalam bentuk matematis dan dicacah berdasarkan pendekatan karakteristik error. Camera Controller melakukan perhitungan dan mengeluarkan hasil pengukuran dalam bentuk sinyal digital. Camera Controller yang digunakan memiliki built in $1 / 0$ Interface, sementara standard Personal Computer tidak memiliki Interface I/O. Untuk mengatasi hal ini digunakan device DAQ dari National Instrument sebagai interface $\mathrm{I} / \mathrm{O}$ dari Personal Computer, sementara protocol yang digunakan antara DAQ dengan personal computer adalah Ethernet IP Communication.

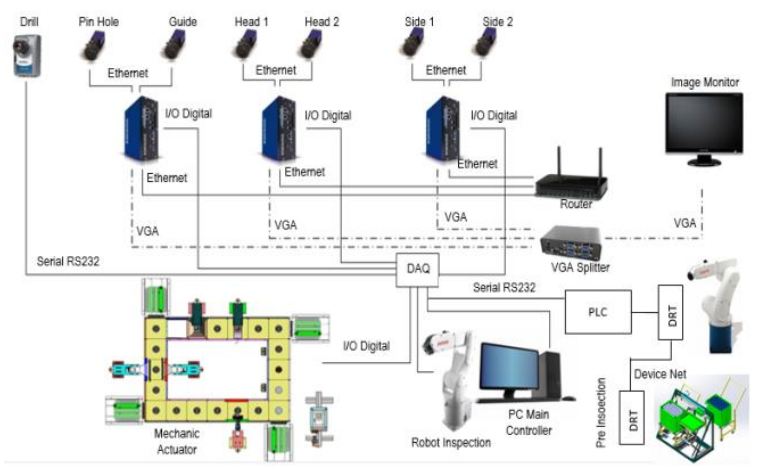

Gambar 30 Diagram Pengolahan Data Inspeksi dan Control
Data yang diterima oleh PC sudah dapat langsung diolah dalam format Microsoft Excel (*.xlsx). Data base ini akan disimpan dalam file Microsoft Excel dan secara otomatis file akan dinamai sesuai dengan tanggal dan jam ketika proses collecting data base dimulai (12112015-17.45 : Tanggal 12, Bulan November, Tahun 2015, Pukul 17.45). Banyaknya data base yang disimpan dapat dibatasi, dalam aplikasi di sistem ini data base akan dihapus secara otomatis dalam jangka waktu 1 (satu) tahun. Data base ini dapat di download serta dijadikan histori dan bahan analisis bagi customer.

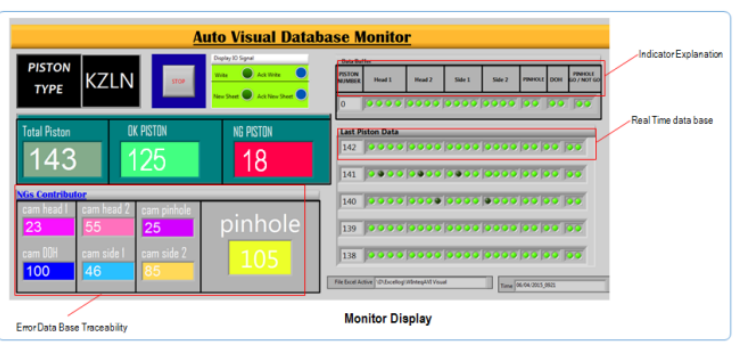

Gambar 31 Display Monitor pada Mesin Inspeksi

\section{Kesimpulan}

Beberapa yang perlu diperhatikan dalam membangun suatu sistem inspeksi visual dengan menggunakan aplikasi kamera, diantaranya :

a. Objek yang akan di inspeksi harus benar-benar bersih dari kontaminasi luar, seperti kotoran, tulisan,jamur,dll. Hal tersebut dapat dibaca oleh kamera menjadi sebuah cacat. Oleh sebab itu dalam sistem ini ditambahkan pre-inspeksi untuk memastikan piston bersih dan kering.

b. Terkait dengan penggunaan sistem kamera, dimana sistem/area tersebut telah dikondisikan pencahayaannya, temperatur dan kelembapannya. Adapun tuntutan kondisi lingkungan untuk sistem ini adalah : Temperature $\quad: 23^{\circ} \mathrm{C}$ Humidity $\quad: 50 \%$ Lighting Intensity : : 800 lumen

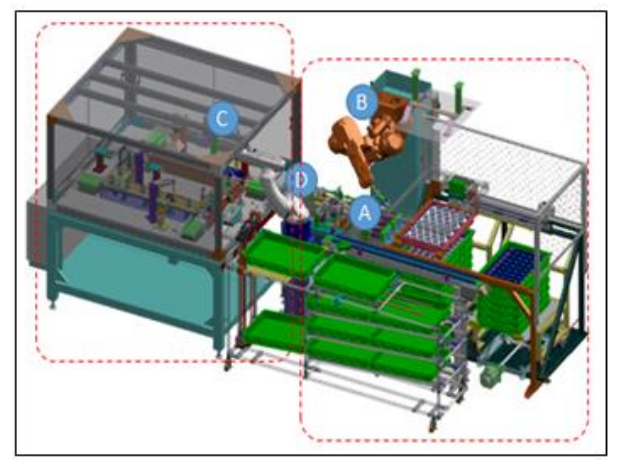

Gambar 32 Layout Mesin Auto Inspeksi Visual

\section{A. Proses Pre-Inspeksi}


$\checkmark$ Pemebersihan dan Pengeringan

$\checkmark$ Vision Guide Robto (VGR)

$\checkmark \quad$ Inspeksi Area Pin Hole

B. Fungsi Robot \#1

$\checkmark$ Menangani piston dari keranjang input sampai dengan pre-inspeksi

C. Proses Inspeksi Visual Auto

$\checkmark$ Inspeksi Area Kepala

$\checkmark$ Inspeksi Area Sisi Kanan

$\checkmark \quad$ Inspeksi Area Sisi Kiri

$\checkmark \quad$ Inspeksi Area Lubang Oli

\section{Fungsi Robot \#2}

$\checkmark$ Menangani piston dari pre-inspeksi, auto inspeksi visual dan memisahkan serta menyusun piston OK dan NG

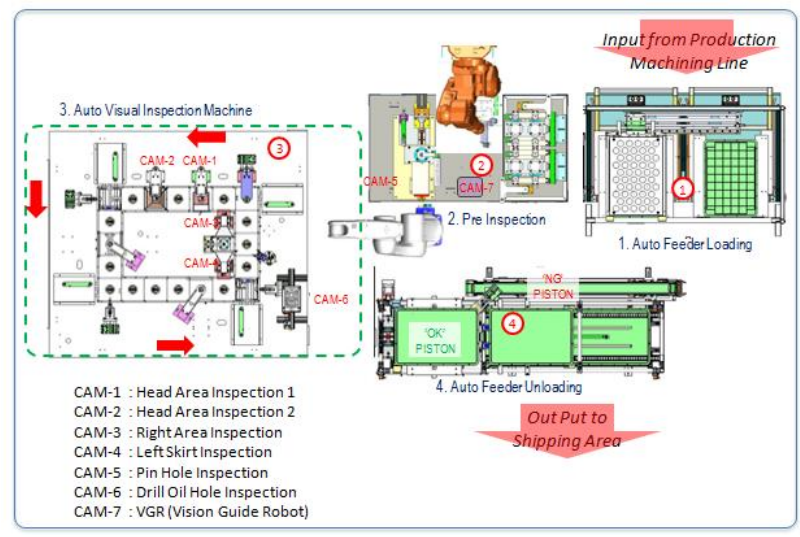

Gambar 33 Alur Proses Mesin Auto Inspeksi Visual

\section{Ucapan Terima Kasih}

[1] Seluruh jajaran Manajemen dan Karyawan PT Astra Otoparts Tbk Divisi Winteq.

[2] Seluruh jajaran Manajemen dan Karyawan PT Federal Izumi Manufacturing.

[3] Seluruh tim yang terlibat dalam projek ini, tim design dan tim assembly Mechanic, Elektrik \& Robotik.

\section{Daftar Pustaka}

[1] PT Federal Izumi Manufacturing, "Piston Knowledge 1" Bogor 2004.

[2] Rosa dan Colligan, Ergonomi fisik, Fisiologi manusia kerja, 1997. (http://ergonomifit.blogspot.co.id/2012/04/ritme-circadianjam-biologis-manusia.html)

[3] Academia, "Lembar Praktiku", http://www.academia.edu/8425595/LEMBAR KERJA_PRAKTIKUM_DEFINISI_OTOMASI_Oto masi_Industri, (diakses pada 19 Oktober 2015)

[4] Vision System, "Cameras", http://www.visionsystems.com/cameras.htm, (diakses pada 19 Oktober 2015)

[5] Kamera Digital, "Penertian Kamera dan Sejarahnya", http://daftarkameradigitalberkualitas.blogspot .co.id/2013/02/pengertian-kamera-dansejarahnya.html, (diakses pada 19 Oktober 2015)

[6] ABB, (2013).Operation Manual Instruction to RAPID, [pdf].Sweden.ABB. 